\title{
Research on the Problems and Countermeasures in the Effective Connection of Rural Poverty Alleviation Policies in the Post-poverty Era
}

\author{
Weibo Qiu ${ }^{1, *}$ Penghao $\mathrm{Li}^{1}$ Daliang $\mathrm{Li}^{1}$ \\ ${ }^{1}$ Guangdong Nanhua Vocational College of Industry and Commerce, Guangzhou, Guangdong 510507, China \\ *Corresponding author. Email: 593920797@qq.com
}

\begin{abstract}
Based on empirical research, this project combined questionnaire survey method and in-depth interview method to obtain 255 valid questionnaires and 6 interview records. According to interviews and data analysis, the following conclusions are drawn: 1 . Nearly half of the people don't understand poverty alleviation policies; 2 . The main way for villagers to understand policies is through village committee propaganda and word of mouth; 3. The poverty alleviation policies that the villagers are concerned about are mainly related to daily life and medical care; 4. The most important thing for rural poverty alleviation is to achieve medical security and material subsidies; 5 . Nearly half of the villagers believe that poverty alleviation policies are helpful; 6 . Poverty alleviation policies should be improved in terms of publicity, review procedures, assistance projects, and degree of emphasis; 7. The help that villagers most need from the government is focused on providing financial support, providing employment opportunities, solving difficulties in life, and providing technical assistance. Suggestions for existing problems: 1 . Intensifying the publicity and popularization of poverty alleviation policies, and ensuring that policies "into the village, into the household, and into the brain"; 2. Promoting effective communication between poverty alleviation cadres and local villagers, and eliminating information asymmetry; 3. Alleviating the poverty as well as improving the wisdom and spirit, and solving the problem of intergenerational transmission of poverty from ideological roots; 4. Improving the rural social security policy and serious illness medical insurance to provide the villagers with bottom covered security; 5 . The formulation of policies must be effectively linked to ensure the continued stability of the overall policy.
\end{abstract}

Keywords: Rural revitalization, Poverty alleviation, Implementation, Problems and countermeasures.

\section{INTRODUCTION}

General Secretary Xi Jinping pointed out the need to maintain a stable policy for poverty alleviation at the Symposium on Decisive Victory of Poverty Alleviation. During the transitional period, it is a must to strictly implement the requirements of removing the label of poverty without removing the responsibility, removing the label of poverty without removing the policy,

*Fund: General Project of 2020 Guangdong Province Science and Technology Innovation Strategy Special Fund (College Students Science and Technology Innovation Cultivation) — The Current Situation, Predicament and Breakthrough of Rural Decisive Poverty Alleviation Against the Background of Targeted Poverty Alleviation — Results Based on a Typical Survey of Rural Areas in Ruyuan Yao Autonomous County, Shaoguan (Project Number: pdjh2020b1115). removing the label of poverty without removing the assistance, and removing the label of poverty without removing the supervision. The main policy measures cannot stop suddenly, and the villagestationed working crew cannot be withdrawn. It can be seen that how to achieve an effective connection between poverty alleviation and the strategy of rural revitalization is a difficult problem faced by the grassroots rural areas.

The implementation of the rural poverty alleviation policy is directly related to the stability of the poverty alleviation policy, and is directly related to whether the poverty alleviation strategy can be effectively connected with the rural revitalization strategy. Therefore, this project takes the grassroots rural area as a typical representative, 
and investigates the villagers' understanding of the national targeted poverty alleviation policy, the evaluation of the implementation, and the local poverty alleviation cadres' implementation of the targeted poverty alleviation policy, discovers the existing problems and difficulties, and studies and judges the local pain points and difficulties in the process of targeted poverty alleviation and poverty alleviation, which are of great significance to truly understand and grasp the targeted poverty alleviation situation at the most basic level, and are also important ways to measure the actual effect of poverty alleviation, and have profound practical and social significance.

\section{RESEARCH STATUS IN CHINA AND FOREIGN COUNTRIES}

Due to the relatively late introduction of precision poverty alleviation and poverty alleviation, foreign scholars have relatively few studies directly related to these two concepts. Their research in this field is more about poverty alleviation, and their focus on poverty alleviation is more reflected in: 1. Summary of poverty alleviation experience: For example, based on a detailed investigation of the current situation of urban poverty in Zimbabwe, Banda, Collium: Van der Merwe, IJ (2017) found that the church plays a role that cannot be ignored in poverty reduction; 2 . Discussion on poverty alleviation models: Suich, Helen; Howe, Caroline; Mace, Georgina (2015) and others questioned the ecological poverty alleviation model, and believed that ecological poverty alleviation couldn't fundamentally eliminate poverty; 3. Research on poverty alleviation theories: For example, Barrett, Christopher B.; Garg, Teevrat; McBride, Linden (2016) used the theory of poverty trap and pointed out that the poverty trap was the result of self-reinforcing poverty due to the balanced behavior of the poor and their underlying mechanisms; 4. Construction of poverty alleviation mechanism: For example, Constance Gunhidzirai, Pius T. Tanga (2017) and others analyzed the poverty alleviation mechanism of informal entrepreneurship in Zimbabwe and pointed out its fatal flaws.

In terms of research in China, a search was conducted on CNKI on the topic of "Poverty Alleviation Policies in the Post-poverty era", and a total of 14 documents were obtained. The basic research situation is summarized as follows: 1 . Research on the adjustment and optimization of poverty alleviation policies: He Huijiang (2020) focused on the adjustment and optimization strategies of anti-poverty policies[2], Li Hong, Liu Qing, and Zhang Yuheng (2020) focused on exploring the limits of poverty alleviation policies and their optimization paths[7], and Kang Yanhua, Dou Xiaoqiang, Zhang Mingchun, and Wang Xiaojuan (2019) studied the effective extension strategies of financial poverty alleviation policies by taking fixed poverty counties as examples[8]. 2 . Research on the risk of poverty-returning and governance: Xu Guanqin (2020) analyzed the risk of farmers returning to poverty and proposed corresponding governance countermeasures based on the perspective of collaborative governance[4], Liu Yan (2020) reviewed the relevant research on the "risk of poverty-returning and insurance against poverty" and put forward pertinent suggestions[5], and Liu Jian (2021) explored the construction path of an endogenous poverty governance system from a family-based perspective [1]. 3. Research on the stability of poverty alleviation policies: Xia Qi (2020) used Suixi County as a typical case to summarize and refine a stable system and mechanism to consolidate the effectiveness of poverty alleviation [3]. 4. Policy audit research: Wang Wenting (2020) analyzed the trend of performance audit of poverty alleviation policies in the context of the post-poverty era, and made policy recommendations accordingly [6].

\section{OVERVIEW OF THE SURVEY}

Taking rural villagers as the survey object, through the combination of questionnaire survey method and interview method, this article obtained 255 valid questionnaire samples and 6 interview samples, and used SPSS17.0, EXCEL2010 and other software to analyze the data.

\section{DATA ANALYSIS AND CONCLUSION}

\subsection{Analysis of Understanding of National Poverty Alleviation Policies}

Data analysis shows that $50.20 \%$ of the villagers understand national poverty alleviation policies, and $49.80 \%$ of the villagers don't understand national poverty alleviation policies. The data shows that nearly half of the people still don't understand poverty alleviation policies. It can be seen that the government also needs to increase publicity of national poverty alleviation policies and pay attention to "efficiency" in the process of 
popularization, so as to "enter villages, households and homes".

\subsection{Analysis of Ways to Understand Poverty Alleviation Policies}

Data show that $61.72 \%$ of villagers understand poverty alleviation policies through the village committee's propaganda, and $48.44 \%$ of villagers understand through word of mouth of relatives, friends, neighbors, etc., $41.41 \%$ of the villagers understand through newspapers, radio and television and other news media, and $40.63 \%$ of the villagers know about policies through government public documents. The data shows that most villagers learn about poverty alleviation policies through village committee propaganda, followed by word-of-mouth propaganda of relatives, friends and neighbors, and news media such as newspapers, radio and television, showing that the mode of propagating poverty alleviation policies is relatively traditional and unitary, and also explaining why $49.80 \%$ of villagers don't understand national policies.

\subsection{Analysis of Relevant Paths and Measures to Learn About Targeted Poverty Alleviation and Poverty Alleviation}

The data shows that what $33.30 \%$ of the villagers have known about the targeted poverty alleviation path and related measures is the bottom covered security of social poverty alleviation, what $30.60 \%$ of the villagers have learned about is poverty alleviation through education, and what $22.00 \%$ of the villagers have learned about is poverty alleviation through industrial development. It can be seen that what over $30 \%$ of the villagers have learned about the path and related measures for targeted poverty alleviation is the bottom covered security of social poverty alleviation or poverty alleviation through education. In short, most of the villagers learned about poverty alleviation paths and measures related to life and health, which is also inseparable from the publicity of these aspects by relevant departments.

\subsection{Analysis of the Understanding of Targeted Poverty Alleviation Projects}

The data shows that what $34.10 \%$ of the villagers understand targeted poverty alleviation projects is poverty alleviation through medical assistance, what $31.40 \%$ of the villagers understand targeted poverty alleviation projects is poverty alleviation through minimal social security policy and what $23.90 \%$ of the villagers understand targeted poverty alleviation projects is poverty alleviation through building houses. According to the data, what most villagers understand is related to their own needs. According to Maslow's demand theory, the villagers are at the level of physiological needs, indicating that the local economic development level is low.

\subsection{Analysis of the Understanding of the Policies of Household Enjoying the Minimum Living Guarantee and Household Enjoying the Five Guarantees}

The data shows that $40.63 \%$ of the villagers have heard of but do not understand the policies of household enjoying the minimum living guarantee and household enjoying the five guarantees. $39.84 \%$ of the villagers have heard of and have a little understanding of the policy content of household enjoying the minimum living guarantee and household enjoying the five guarantees. $9.38 \%$ of the villagers have heard of and have certain understanding of standards and policy content of household enjoying the minimum living guarantee and household enjoying the five guarantees. It can be seen that there are still very few people who have fully understood the standards and content of the policies of household enjoying the minimum living guarantee and household enjoying the five guarantees.

\subsection{Analysis of the Most Critical Content That Needs to Be Done in Rural Poverty Alleviation}

The data shows: $32.90 \%$ of the villagers feel that the most critical content of poverty alleviation in rural areas is medical security. $29.40 \%$ of the villagers feel that the most critical content for rural poverty alleviation is material subsidies, and $25.10 \%$ of the villagers feel that the most critical content for rural poverty alleviation is to promote employment. It can be seen that the most important thing for rural poverty alleviation is to achieve medical security and material subsidies. According to the interview and investigation in the village, many villages are far away from medical institutions, and it is very inconvenient for villagers to seek medical treatment. 


\subsection{Analysis of the Help Given by the Government}

The data shows that $14.10 \%$ of the villagers are given material subsidies by the government, $10.60 \%$ of the villagers are supported by government funds or loans, and $9.00 \%$ of the villagers are funded by the government for education. It can be seen that the material living conditions in some rural areas are still lacking, and the villagers' lives are less guaranteed. At the same time, there is not enough money for them for life management. The problem of children in rural families going to school still needs to be resolved.

\subsection{Analysis of the Help That Poverty Alleviation Policies Bring to the Rural Groups in Difficulty}

The data shows that $37.30 \%$ of the villagers believe that government's poverty alleviation policies have provided general help to rural households in difficulties, $22.00 \%$ of the villagers believe that these policies have brought great help, and $14.50 \%$ of the villagers believe that these policies have brought a lot of help. According to offline interview and investigation, most of the villagers do not meet the criteria of poor households. These people are busy with their lives and are not clear about the implementation of government policies.

\subsection{Analysis of Actively Understanding National Poverty Alleviation Policies}

The data shows that $78.00 \%$ of villagers will take the initiative to learn about the country's poverty alleviation policies when they and their families need help, $29.00 \%$ of the villagers will take the initiative to learn about the country's poverty alleviation policies when their relatives and friends need help, and $25.50 \%$ of the villagers will take the initiative to learn about the poverty alleviation policies under other circumstances. It can be seen that most villagers take the initiative to learn about poverty alleviation policies when they and their families need help, which is related to the traditional Chinese family culture.

\subsection{Analysis of the Help That Poverty Alleviation Policies Bring to the Rural Difficult Individuals}

The data shows that $42.70 \%$ of the villagers think that poverty alleviation policies will help the rural groups in difficulties to some extent, $23.10 \%$ of the villagers think that they are slightly helpful, and $14.10 \%$ of the villagers think that they are more helpful. According to data, most villagers believe that poverty alleviation policies will help the rural groups in difficulties to some extent, followed by "slightly helpful". It can be seen that local poverty alleviation policies have a positive effect, but there are also deficiencies.

\subsection{Analysis of the Government's Emphasis on Poverty Alleviation}

The data shows that $47.10 \%$ of the villagers believe that the government generally attaches importance to local poverty alleviation work, $22.40 \%$ of the villagers believe that the government pays more attention to local poverty alleviation work, and $13.30 \%$ of the villagers believe that the government attaches importance to local poverty alleviation work occasionally. It can be seen that over $40 \%$ of villagers believe that the government generally attaches importance to local poverty alleviation.

\subsection{Analysis of Hoping to Understand National Poverty Alleviation Policies}

The data shows that $69.80 \%$ of the villagers want to know the medical insurance in national poverty alleviation policies, $53.70 \%$ of the villagers want to know about education funding, and $52.90 \%$ of the villagers want to know about household enjoying the minimum living guarantee and household enjoying the five guarantees. The data shows that nearly $70 \%$ of villagers want to know about medical insurance.

\subsection{Analysis of the Aspects of National Poverty Alleviation Policies That Need to Be Improved}

The data shows: $58.00 \%$ of villagers feel that national poverty alleviation policies need to increase publicity, $56.90 \%$ of the villagers believe that relevant government departments should pay more attention, $54.90 \%$ of the villagers feel that more poverty alleviation projects should be added, and $43.10 \%$ of the villagers believe that the review 
procedures should be simplified. According to the data, nearly $60 \%$ of villagers believe that the national poverty alleviation policy needs to increase publicity.

\subsection{Analysis of Poverty Alleviation Measures to Be Taken by the Government Hoped by Villagers}

Statistics show that $58.40 \%$ of the villagers hope that the government can provide financial support for their families, $45.10 \%$ of the villagers hope that the government can provide employment opportunities for their families and solve life difficulties, and $32.50 \%$ of the villagers hope that the government can provide technical assistance to their families. The data shows that nearly $60 \%$ of villagers hope that the government will provide financial support, solve life difficulties or provide employment opportunities. According to the interview and investigation in this survey, the elderly need more financial support to solve their difficulties in life, while the young and middle-aged people need technical and employment assistance. It can be seen that the local economy is underdeveloped and the villagers lack labor skills and employability.

\subsection{Analysis of Satisfaction with the Government's Poverty Alleviation Work}

The data shows that $46.70 \%$ of the villagers are generally satisfied with the government's poverty alleviation work, $31.40 \%$ of the villagers are satisfied with the government's poverty alleviation work, and $9.40 \%$ of the villagers are dissatisfied with the government's poverty alleviation work. According to the data, nearly $50 \%$ of the villagers are generally satisfied with the government's poverty alleviation work, and only few villagers are very satisfied. According to the interview and investigation in this survey, the relevant staff pay attention to the process of poverty alleviation work, and fail to really understand the needs of the villagers. It can be seen from this that the government must diversify its poverty alleviation methods, and combine material assistance with psychological care.

\section{PROBLEMS AND COUNTERMEASURES}

\subsection{The Understanding and Evaluation of Local Villagers and Village Cadres in Poverty Alleviation Work Are Different}

The villagers' understanding and evaluation of the government's poverty alleviation work is average, while the village cadres are generally satisfied with the poverty alleviation work, which is contradictory. According to data analysis, the local villagers' understanding of poverty alleviation policies is mainly through the village committee's propaganda and word of mouth from relatives, neighbors and friends. Among them, 105 people, accounting for $61.72 \%$, understand these policies through the propaganda of the village committee. It can be seen that the propaganda of the village committee is the main way for local villagers to understand the national policy. However, based on the comparison of data analysis and interview content, some villagers and village cadres only have a superficial understanding of the poverty alleviation policy, and cannot interpret the content of the poverty alleviation policy in detail. After further analysis, it is found that although the implementation and publicity of the poverty alleviation policy by the village cadres follow the procedure, they fail to understand the detailed content of the poverty alleviation policy, so that their publicity is too process-oriented and onesided, as a result, some villagers are unclear and bored with the poverty alleviation policy. All in all, the village cadres must grasp the "5W1H" working method, analyze the actual local situation and understand the real needs of the villagers, and have targeted publicity and implementation of poverty alleviation policies.

\subsection{The Evaluations of Local Villagers and Village Cadres on the Implementation and Assistance of Poverty Alleviation Work Are Contradictory}

It can be seen from the interviews that the village cadres recognize the implementation of the poverty alleviation policy very much, but in the data analysis, the villagers think that the poverty alleviation policy is generally helpful, and the two contradict each other. According to data analysis, interviews with village cadres, combined with local actual conditions, the government's poverty alleviation work has specialized auditing and 
diversified publicity methods. However, among the surveyed villagers, there are middle-aged and elderly people with low academic qualifications and elementary and middle school students who have difficulty understanding the professional vocabulary of poverty alleviation, so their evaluation of the implementation and assistance of poverty alleviation work is average. At the same time, it also precisely shows that the government's propaganda methods and objects of poverty alleviation policies are unitary, so that there are contradictions between data analysis and interview content.

\subsection{The Other Reason That Over 40\% of Local Villagers Are Not Wealthy Is the Influence of Internal and External Environmental Factors}

After discussing and analyzing the data and interview content combined with the actual local situation, it is concluded that: (1) Some villagers have advanced consumption habits and hedonism is more obvious; (2) Some family members of villagers have bad habits such as addiction to gambling and eating their heads off ; (3) Some poor households who have received government relief and have the ability to work but do nothing have developed the negative thinking of "waiting, relying, and asking"; (4) External environmental factors of force majeure cause poverty or even cause poverty-returning, for example, the African Swine Fever in 2018 and the COVID-19 pandemic in 2020 caused local pig farmers to lose money, and the losses caused by the large amount of investment in the early stage were far beyond the economic capacity of the farmers, which led to their bankruptcy; (5) Different external groups have different standards for measuring wealth and poverty.

\section{CONCLUSION}

The issues relating to agriculture, rural areas, and rural people are China's biggest reality. In the post-poverty era, ensuring the stable transition of poverty alleviation policies requires the joint efforts of the state, local governments, social forces and rural villagers. In particular, the key points include: 1. Intensifying the publicity and popularization of poverty alleviation policies, and ensuring that policies "into the village, into the household, and into the brain"; 2. Promoting effective communication between poverty alleviation cadres and local villagers, and eliminating information asymmetry; 3. Alleviating the poverty as well as improving the wisdom and spirit, and solving the problem of intergenerational transmission of poverty from ideological roots; 4. Improving the rural social security policy and serious illness medical insurance to provide the villagers with bottom covered security; 5. The formulation of policies must be effectively linked to ensure the continued stability of the overall policy.

\section{AUTHORS' CONTRIBUTIONS}

Weibo Qiu and Penghao Li are responsible for experimental design, Penghao $\mathrm{Li}$ and Daliang $\mathrm{Li}$ analysed data, Weibo Qiu wrote the manuscript and contributed to revising and editing.

\section{REFERENCES}

[1] Liu Jian. The construction of the endogenous poverty governance system in the post-poverty era - from the family-based perspective [J]. Journal of Fujian Agriculture and Forestry University (Philosophy and Social Sciences Edition), 2021, 24(01): 16-25. (in Chinese)

[2] He Huijiang. The Adjustment and Optimization of China's Anti-poverty Policy in the Post-poverty Era [J]. Academic Journal of Zhongzhou, 2020(12):89-93. (in Chinese)

[3] Xia Qi. Stability study on the effectiveness of poverty alleviation in the "post-poverty era" of Suixi County [D]. Anhui University of Finance and Economics, 2020. (in Chinese)

[4] Xu Guanqin. The risk of farmers returning to poverty in the post-poverty era from the perspective of collaborative governance and the governance countermeasures [J]. Straits Science, 2020(11):59-61+96. (in Chinese)

[5] Liu Yan. A Review of Researches on the Risk of Returning to Poverty and Insurance Antipoverty in the "Post-Poverty Era" [J]. Journal of Anhui Agricultural Sciences, 2020,48(16):28-29+66. (in Chinese)

[6] Wang Wenting. Analysis of the performance audit situation of poverty alleviation policies in the post-poverty era [J]. Audit Monthly, 2020(08):18-21. (in Chinese)

[7] Li Hong, Liu Qing, Zhang Yuheng. Limits and optimization paths of poverty alleviation policies in the post-poverty era $[\mathrm{J}]$. Society 
and Public Welfare, 2020(06):93-94+97. (in Chinese)

[8] Kang Yanhua, Dou Xiaoqiang, Zhang Mingchun, Wang Xiaojuan. Study on the Extension Strategy of Financial Poverty Alleviation Policy in National Poverty Counties in the Post- Poverty Era [J]. Journal of Guangxi Financial Research, 2019(01):6776. (in Chinese) 